Jurnal Ilmiah ESAI Volume 13, No. 2, Juli 2019

p-ISSN 1978-6034 e-ISSN 2580-4944

The effects of skepticism, auditor experience, and self-efficacy on audit judgments at the Public Accountant Office in Medan

\title{
Pengaruh Skeptisme, Pengalaman Auditor, dan Self Efficacy Terhadap Audit Judgement Pada Kantor Akuntan Publik di Medan
}

\author{
Vera Yowanda ${ }^{1)}$,Vini Kristina ${ }^{2)}$, Riki Pernando ${ }^{3)}$,Sherly ${ }^{4)}$,Erika ${ }^{5}$, Wilsa Road Betterment \\ Sitepu ${ }^{()}$, Rika Dinarianti ${ }^{7}$ \\ ${ }_{1,2,3,4,5,6)}$ Program Studi Akuntansi Audit Pada Jurusan Ekonomi Universitas Prima Indonesia \\ Medan \\ 7) Program Studi Akuntansi Pada Jurusan Ekonomi Universitas Prima Indonesia Medan \\ e-mail:yowanda.vera@yahoo.com
}

\begin{abstract}
Judgment audit is a consideration made by public accountants in making an audit plan, and before issuing an opinion on the company's financial statements. The independent variables of this study are skepticism, auditor experience, and self efficacy. The dependent variable of this study is judgment audit. The purpose of this study is to examine and analyze the influence of skepticism, auditor experience, and self efficacy on judgment audits at the Public Accountant Office in Medan. This research uses descriptive quantitative research methods with the nature of research of causal relationships. The data were collected with questionnaires which were tested for validity and reliability before conducting the research. The test equipment used is normality test, multicollinearity test, and heteroscedasticity test. This study uses purposive sampling with a total of 90 respondents in the Public Accountant Office in Medan. The results of the study on the hypothesis indicate that skepticism, auditor experience, and self efficacy partially and simultaneously influence the judgment audit on the Public Accounting Firm in Medan. The conclusion of this study shows that skepticism, auditor experience, and self-efficacy have a positive and significant effect on judgment audits at the Public Accountant Office in Medan.
\end{abstract}

Keywords: Skepticism, Auditor Experience, Self Efficacy, Audit Judgment

\section{Pendahuluan}

Perkembangan bisnis yang terjadi saat ini menyebabkan meningkatnya kebutuhan berbagai pihak terhadap laporan keuangan sebagai penyedia informasi baik untuk pihak internal (manajemen) maupun pihak eksternal (investor, kreditur, dan pemerintah). Laporan keuangan memiliki banyak fungsi bagi kedua pihak tersebut, namun secara umum digunakan untuk melihat kondisi keuangan perusahaan. Laporan keuangan perusahaan yang hendak di-publish harus telah diaudit oleh pihak eksternal yang independen yaitu akuntan publik, guna menjadi jaminan bahwa laporan keuangan tersebut andal, relevan, dan tentunya bebas dari salah saji yang material.

Sebuah laporan keuangan yang telah diaudit oleh auditor harus bisa menjamin kualitas dari setiap informasi yang 
dihasilkannya. Untuk dapat menyeleksi informasi tersebut maka diperlukan suatu audit judgement dari auditor. Audit judgement ini berupa pertimbangan khusus bagi auditor dalam melakukan proses audit, baik itu ketika menerima perikatan dengan klien, membuat perencanaan audit, serta ketika auditor akan mengeluarkan suatu opini audit. Audit judgement diperlukan karena audit yang dilakukan tidak menyeluruh terhadap seluruh bukti yang ada, dimana bukti ini kemudian akan digunakan untuk menyatakan opini atas laporan keuangan perusahaan yang telah diaudit, dengan demikian secara tidak langsung audit judgement telah menentukan hasil dan kualitas dari pelaksanaan audit serta dapat menunjukkan kinerja seorang auditor dalam melaksanakan tugasnya.

Sikap skeptisme diperlukan dalam diri seorang auditor karena skeptisme mendorong auditor agar dapat berpikir lebih kritis, selalu mempertanyakan dan waspada disaat melakukan audit. Sikap skeptisme juga dapat membantu auditor dalam memeriksa laporan keuangan sehingga salah saji yang disebabkan oleh kecurangan klien dapat terhindarkan. Selain itu, skeptisme penting saat penilaian bukti audit yang juga mencakup pertimbangan mengenai kecukupan dan ketepatan bukti audit. Dengan demikian, seorang auditor yang memiliki sikap skeptisme diharapkan mampu membuat audit judgement (pertimbangan audit) yang lebih tepat.
Setelah sikap skeptisme seorang auditor, pengalaman juga dinilai sebagai salah satu faktor yang mampu mempengaruhi auditor dalam pembuatan pertimbangan secara teknis. Pengalaman umumnya dikaitkan dengan masa kerja, pengetahuan, dan keterampilan. Pengalaman auditor didasari pada asumsi bahwa tugas audit yang dilakukan secara berulang-ulang dalam kurun waktu tertentu memberikan peluang pelaksanaan audit yang semakin baik. Auditor yang telah lama bekerja akan memperoleh banyak pengalaman yang mampu menunjang peningkatan kinerjanya dalam pelaksanaan audit, contohnya kemampuan auditor mengolah informasi suatu laporan keuangan yang tidak relevan dengan memprediksi kecurangan yang dilakukan klien serta menemukan salah saji yang material. Peningkatan kinerja bagi auditor yang berpengalaman dapat juga meliputi pembuatan audit judgement yang lebih baik.

Ada pula self efficacy yang diyakini bahwa apabila dimiliki oleh auditor maka ia akan cenderung melakukan pertimbangan mengenai informasi yang telah diperoleh sebelum memutuskan sebuah pilihan. Self efficacy sendiri dikenal sebagai efikasi diri yang dinyatakan sebagai suatu rasa kepercayaan bahwa seseorang mampu menjalankan tugas pada tingkat tertentu, yang mempengaruhi aktivitas pribadi terhadap pencapaian tujuan. Sehingga auditor yang memiliki self efficacy tinggi cenderung 
melakukan tanggung jawabnya sebagai auditor dengan baik dan tentunya disertai dengan adanya pertimbangan (judgement) yang lebih tepat.

Salah satu kasus kegagalan audit yang belum lama ini terjadi atas laporan keuangan PT Indosat Tbk pada tahun 2011 yang dilakukan oleh partner Ernst and Young (EY) di Indonesia yaitu KAP Purwanto, Suherman, dan Surja. Kasus ini mengakibatkan Ernst and Young (EY) di Indonesia diberikan denda US\$ 1 juta dan denda terhadap akuntan publik partner EY Indonesia Roy Iman Wirahardja sebesar US\$ 20.000 ditambah larangan berpraktek selama lima tahun, kemudian mantan Direktur EY Asia-Pacific, Randall Leali diberikan denda sebesar US\$ 10.000 dan larangan praktek satu tahun oleh Public Company Accounting Oversight Board (PCAOB). Hukuman ini dijatuhkan karena KAP EY Indonesia telah gagal menyajikan bukti yang mendukung perhitungan atas sewa 4.000 menara seluler yang terdapat dalam laporan keuangan Indosat. KAP EY Indonesia memberikan pendapat Wajar Tanpa Pengecualian (WTP) terhadap laporan keuangan tersebut, padahal perhitungan dan analisisnya belum selesai. (http://nasional.kontan.co.id/news/mitraernst-young-indonesia-didenda-us-1-juta)

Berdasarkan kasus diatas dapat disimpulkan bahwa partner Ernst and Young (EY) di Indonesia yang bertanggung jawab atas laporan keuangan PT Indosat Tbk tahun 2011 tidak melaksanakan tugas audit dengan maksimal. Kelalaian akuntan publik partner EY Indonesia dalam pembuatan audit judgement seperti memberikan opini Wajar Tanpa Pengecualian (WTP) dikarenakan auditor yang bertanggung jawab perlu meningkatkan sikap skeptismenya, sehingga auditor lebih kritis dan waspada disaat melaksanakan pemeriksaan audit. Pengalaman auditor dan self efficacy yang tinggi juga diperlukan saat auditor melakukan tugas audit agar auditor mampu membuat audit judgement yang lebih baik dan tepat.

Berdasarkan latar belakang diatas, maka peneliti merumuskan masalah sebagai berikut: 1) bagaimana pengaruh skeptisme terhadap audit judgement pada Kantor Akuntan Publik di Medan; 2) bagaimana pengaruh pengalaman auditor terhadap audit judgement pada Kantor Akuntan Publik di Medan; 3) bagaimana pengaruh self efficacy terhadap audit judgement pada Kantor Akuntan Publik di Medan; dan 4) bagaimana pengaruh skeptisme, pengalaman auditor, dan self efficacy terhadap audit judgement pada Kantor Akuntan Publik di Medan.

Penelitian ini bertujuan untuk: 1) menguji dan menganalisis pengaruh skeptisme terhadap audit judgement pada Kantor Akuntan Publik di Medan; 2) menguji dan menganalisis pengaruh pengalaman auditor terhadap audit judgement pada Kantor Akuntan Publik di Medan; 3) menguji dan menganalisis pengaruh self efficacy terhadap audit judgement pada Kantor 
Akuntan Publik di Medan; dan 4) menguji dan menganalisis pengaruh skeptisme, pengalaman auditor, dan self efficacy terhadap audit judgement pada Kantor Akuntan Publik di Medan.

\section{Landasan Teori}

\section{Teori Skeptisme}

Menurut S Iriantika dan I Ketut (2017:1060), skeptisme profesional auditor merupakan sikap (attitude) auditor dalam melakukan penugasan audit dimana sikap ini mencakup pikiran yang selalu mempertanyakan dan melakukan evaluasi secara kritis terhadap bukti audit.

Menurut Operasianti et al. (2015) skeptisme profesional pada Kantor Akuntan Publik diukur melalui tiga hal, yaitu: 1) memeriksa dan menguji bukti; 2) memahami penyedia informasi; dan 3) mengambil tindakan atas bukti

\section{Teori Pengalaman Auditor}

Menurut Nadirsyah et al. (2011), pengalaman audit adalah pengalaman yang dimiliki seorang auditor dalam melakukan pemeriksaan dari banyaknya penugasan berbeda yang pernah dilakukan dan juga lamanya auditor menjalankan profesinya serta dapat menambah pengetahuannya mengenai pendeteksian kekeliruan.

Menurut Praditaningrum (2012), pengalaman auditor diukur dengan dua indikator, yaitu: 1) lamanya bekerja, dan 2) banyaknya tugas pemeriksaan.

\section{Teori Self Efficacy}

Menurut Bandura (2006) dalam Suwandi (2015 : 5), self efficacy merupakan suatu rasa kepercayaan atau keyakinan yang berasal dari motivasi dalam diri bahwa dia mampu untuk melakukan atau mengatur suatu pekerjaan pada tingkatan tertentu, dimana bagi seorang auditor yang memiliki kepercayaan yang tinggi dan memiliki semangat kerja yang tinggi akan berdampak pada kehandalan audit judgement yang dibuatnya.

Menurut Iskandar dan Zuraidah (2011), terdapat 4 macam indikator self efficacy, yaitu: 1) Menilai kepercayaan diri mereka bahwa mereka mampu menyelesaikan tugas audit dengan benar; 2) Kemampuan menghadapi tantangan dalam tugas audit; 3) Kemampuan mengelola persyaratan atau menyelesaikan tugas audit; dan 4) Kepercayaan bahwa mereka mampu melaksanakan tugas audit dengan baik meskipun tugas audit semakin kompleks.

\section{Teori Audit Judgement}

Menurut Sari dan Endang (2017 : 25) audit judgement merupakan suatu pertimbangan pribadi atau cara pandang auditor dalam menanggapi informasi yang mempengaruhi dokumentasi bukti audit serta pembuatan keputusan pendapat auditor atas laporan keuangan suatu entitas.

Menurut Gracea et al. (2017:2631), terdapat 3 macam indikator audit judgement, yaitu: 1) Tingkat materialitas; 2) Tingkat 
risiko audit; dan 3) Kelangsungan hidup suatu entitas

\section{Pengaruh Skeptisme Terhadap Audit Judgement}

Menurut Prihandono (2012 : 4), skeptisisme profesional akan membantu auditor dalam menilai dengan kritis resiko yang dihadapi dan memperhitungkan resiko tersebut dalam bermacam-macam keputusan untuk menerima atau menolak klien, memilih metode dan teknik audit yang tepat, menilai bukti-bukti yang dikumpulkan dan seterusnya.

\section{Pengaruh Pengalaman Auditor Terhadap Audit Judgement}

Menurut Magdalena et al. (2014), auditor yang tidak berpengalaman akan melakukan atribusi kesalahan lebih besar dibandingkan dengan auditor yang berpengalaman. Seorang auditor profesional harus mempunyai pengalaman yang cukup tentang tugas dan tanggung jawabnya. Pengalaman auditor akan menjadi bahan pertimbangan yang baik dalam mengambil keputusan dalam tugasnya.

\section{Pengaruh Self Efficacy Terhadap Audit Judgement}

Menurut Iskandar dan Zuraidah (2011:30), self efficacy yang tinggi akan meningkatkan kinerja audit judgement. Seorang individu dengan memiliki self efficacy yang tinggi akan senantiasa lebih cenderung untuk mempertimbangkan, mengevaluasi, dan menggabungkan kemampuan yang diketahuinya sebelum pada akhirnya dia menentukan suatu pilihan.

\section{Hipotesis Penelitian}

Hipotesis dalam penelitian ini adalah:

$\mathrm{H}_{1}$ : Skeptisme berpengaruh terhadap audit judgement pada Kantor Akuntan Publik di Medan.

$\mathrm{H}_{2}$ : Pengalaman auditor berpengaruh terhadap audit judgement pada Kantor Akuntan Publik di Medan.

$\mathrm{H}_{3}$ : Self efficacy berpengaruh terhadap audit judgement pada Kantor Akuntan Publik di Medan.

$\mathrm{H}_{4}$ : Skeptisme, pengalaman auditor, dan self efficacy berpengaruh terhadap audit judgement pada Kantor Akuntan Publik di Medan.

\section{Metode Penelitian}

Penelitian ini dilakukan pada Kantor Akuntan Publik di Medan yang bersedia untuk mengisi kuesioner. Waktu penelitian dilakukan oleh peneliti dari bulan Mei 2018Maret 2019.

Pendekatan penelitian yang digunakan dalam penelitian ini adalah dengan metode kuantitatif, karena penelitian ini disajikan dengan angka-angka.

Jenis penelitian yang digunakan peneliti adalah penelitian deskriptif. Sifat penelitian yang digunakan adalah penelitian hubungan kausal atau hubungan sebab akibat.

Populasi dalam penelitian ini meliputi auditor-auditor pada Kantor Akuntan Publik di kota Medan sebanyak 23 KAP. Jenis teknik pengambilan sampel yang digunakan dalam penelitian ini yaitu menggunakan 
purposive sampling. Dalam penelitian ini terdapat 90 sampel, jawaban responden sebanyak 30 auditor akan digunakan dalam uji validitas dan reliabilitas, sedangkan sisa responden sebanyak 60 auditor akan digunakan dalam sampel penelitian.

Teknik pengumpulan data pada penelitian ini adalah dengan menggunakan data primer yaitu kuesioner, yang artinya pertanyaan atau pernyataan yang disusun dalam bentuk kalimat sesuai dengan indikator masing-masing variabel.

Data primer dalam penelitian ini diperoleh melalui kuesioner. Sedangkan data sekunder pada penelitian ini diperoleh melalui buku-buku dan jurnal.

\section{Uji validitas dan Reliabilitas}

\section{Uji Validitas}

Suatu kuesioner dikatakan valid jika pertanyaan pada kuesioner mampu untuk mengungkapkan sesuatu yang akan diukur oleh kuesioner-kuesioner tersebut. Uji validitas dilakukan dengan aplikasi Statistical Product and Service Solutions (SPSS) dengan korelasi bivariate antar masingmasing skor indikator. Uji signifikansi dilakukan dengan membandingkan nilai $\mathrm{r}_{\text {hitung }}$ dengan $r_{\text {tabel }}$ untuk degree of freedom $(\mathrm{df})=$ $\mathrm{n}-2$, dalam hal ini $\mathrm{n}$ adalah jumlah sampel. Nilai $r_{\text {tabel }}$ dalam penelitian ini adalah 0,361 .

Tabel 1. Hasil Uji Validitas Variabel Penelitian

\begin{tabular}{lll}
\hline No & Variabel & Keterangan \\
\hline 1 & Skeptisme $\left(\mathrm{X}_{1}\right)$ & Valid \\
2 & Pengalaman Auditor $\left(\mathrm{X}_{2}\right)$ & Valid \\
3 & Self Efficacy $\left(\mathrm{X}_{3}\right)$ & Valid \\
4 & Audit Judgement $(\mathrm{Y})$ & Valid \\
\hline
\end{tabular}

Sumber : Hasil Penelitian, 2019 (Data diolah)

\section{Uji Reliabilitas}

Suatu kuesioner dikatakan reliabel atau handal jika jawaban seseorang terhadap pernyataan adalah konsisten atau stabil dari waktu ke waktu. Pengukuran reliabilitas dapat dilakukan dengan 2 cara yaitu: 1) Repeated measure atau pengukuran ulang: disini seseorang akan diberikan pertanyaan yang sama pada waktu yang berbeda, dan kemudian dilihat apakah ia tetap konsisten dengan jawabannya; dan 2) One shot atau pengukuran sekali saja: disini pengukurannya hanya sekali dan kemudian hasilnya dibandingkan dengan pertanyaan lain atau mengukur korelasi antar jawaban pertanyaan. SPSS memberikan fasilitas untuk mengukur reliabilitas dengan uji statistik cronbach alpha (a). Suatu konstruk atau variabel dikatakan reliabel jika memberikan nilai cronbach alpha $>0,70$. 
Tabel 2. Hasil Uji Reliabilitas Variabel Penelitian

\begin{tabular}{lcccc}
\hline \multicolumn{1}{c}{ Variabel } & Jumlah Pernyataan & Hasil Reliabilitas & Cronbach Alpha & Keterangan \\
\hline Skeptisme $\left(\mathrm{X}_{1}\right)$ & 9 & 0,905 & 0,70 & Reliabel \\
Pengalaman Auditor $\left(\mathrm{X}_{2}\right)$ & 6 & 0,871 & 0,70 & Reliabel \\
Self Efficacy $\left(\mathrm{X}_{3}\right)$ & 12 & 0,899 & 0,70 & Reliabel \\
Audit Judgement $(\mathrm{Y})$ & 9 & 0,870 & 0,70 & Reliabel \\
\hline
\end{tabular}

\section{Hasil Dan Pembahasan}

\section{Statistik Deskriptif}

Statistik deskriptif memberikan gambaran atau deskripsi suatu data yang dilihat dari nilai rata-rata (mean), standar deviasi, varian, maksimum, minimum, sum, range, kurtosis, dan skewness (kemencengan distribusi). Berikut ini adalah hasil statistik deskriptif dari jawaban minimum, maksimum, rata-rata, dan standar deviasi responden :

Tabel 3. Statistik Deskriptif

\begin{tabular}{lccccc}
\hline & $\mathrm{N}$ & Minimum & Maximum & Mean & Std. Deviation \\
\hline Skeptisme & 60 & 24 & 41 & 33,07 & 5,191 \\
Pengalaman Auditor & 60 & 14 & 29 & 21,50 & 4,123 \\
Self Efficacy & 60 & 27 & 55 & 40,78 & 8,038 \\
Audit Judgement & 60 & 20 & 42 & 31,37 & 6,292 \\
Valid N (listwise) & 60 & & & &
\end{tabular}

Sumber : Hasil Penelitian, 2019 (Data diolah)

\section{Hasil Uji Asumsi Klasik}

\section{Uji Normalitas}

Uji normalitas bertujuan untuk menguji apakah dalam model regresi, variabel penganggu atau residual memiliki distribusi normal. Jika uji normalitas ini dilanggar maka data penelitian yang akan diolah menjadi tidak valid.

Histogram

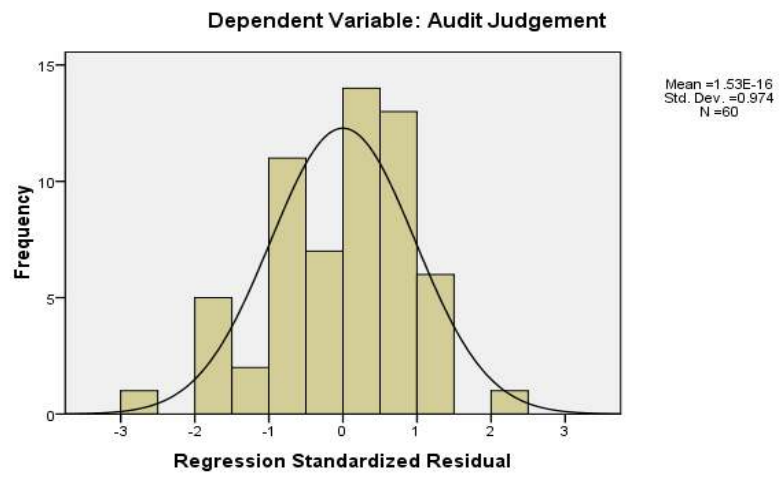

Gambar 1 Hasil Uji Normalitas dengan Grafik Histogram

Sumber : Hasil Penelitian, 2019 (Data Diolah) 
Grafik histogram pada gambar 1 menunjukkan riil membentuk garis kurva cenderung simetris (U) atau menyerupai bentuk lonceng, tidak melenceng ke kiri atau pun ke kanan maka dapat dikatakan data residual berdistribusi normal.

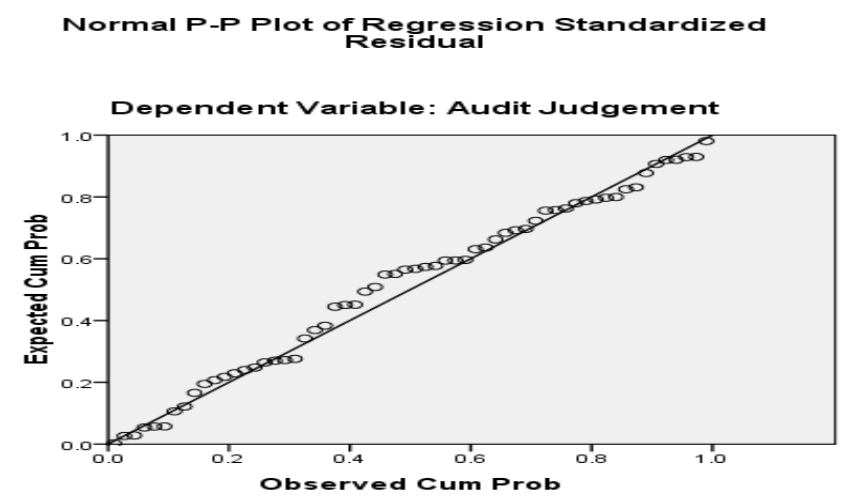

Gambar 2 Hasil Uji Normalitas dengan Grafik Normal Probability Plot Sumber : Hasil Penelitian, 2019 (Data Diolah)

Grafik normal probability plot pada gambar 2 diatas, terlihat titik-titik menyebar disekitar garis diagonal, dan mengikuti garis diagonal. Hal ini menunjukkan bahwa data residual telah berdistribusi normal.

Uji normalitas secara statistik perlu dilakukan untuk memastikan apakah data benar-benar telah berdistribusi normal. Berikut ini adalah uji normalitas secara statistik menggunakan kolmogorov smirnov. Kriteria pengujiannya adalah sebagai berikut :

a. Jika nilai signifikansi $>0,05$, maka data berdistribusi normal

b. Jika nilai signifikansi $<0,05$, maka data tidak berdistribusi normal

Tabel 4 Hasil Uji Normalitas Kolmogorov Smirnov

One-Sample Kolmogorov-Smirnov Test

\begin{tabular}{|c|c|c|}
\hline & & Unstandardized Residual \\
\hline $\mathrm{N}$ & & 60 \\
\hline Normal & Mean & ,0000000 \\
\hline Parameters ${ }^{a, b}$ & Std. Deviation & 3,16293733 \\
\hline & Absolute & 100 \\
\hline $\begin{array}{l}\text { Most Extreme } \\
\text { Differences }\end{array}$ & Positive & 049 \\
\hline & Negative &,- 100 \\
\hline Kolmogorov-Sn & $v z$ &, 776 \\
\hline Asymp. Sig. (2- & &, 584 \\
\hline
\end{tabular}


Hasil uji normalitas kolmogorov smirnov pada tabel 4 menunjukkan nilai signifikansi $0,584>0,05$ dengan demikian dari hasil uji kolmogorov smirnov menunjukkan data terdistribusi normal.

\section{Uji Multikolinearitas}

Uji multikolinearitas bertujuan untuk menguji apakah pada model regresi ditemukan adanya korelasi antar variabel independent. Pada model regresi yang baik seharusnya tidak terjadi korelasi antar variabel independent. Pengujian multikolinearitas dilakukan dengan melihat $\mathrm{VIF} /$ tolerance antar variabel independent dengan kriteria nilai tolerance $<0,10$ atau nilai VIF $<10$.

Tabel 5 Hasil Uji Multikolinearitas

Coefficients

\begin{tabular}{|c|c|c|c|}
\hline \multirow{2}{*}{ Model } & & \multicolumn{2}{|c|}{ Collinearity Statistics } \\
\hline & & Tolerance & VIF \\
\hline \multirow[t]{4}{*}{1} & (Constant) & & \\
\hline & Skeptisme & ,378 & 2,646 \\
\hline & Pengalaman Auditor & ,314 & 3,180 \\
\hline & Self Efficacy &, 331 & 3,019 \\
\hline
\end{tabular}

a. $\quad$ Dependent Variable: Audit Judgement

Sumber: Hasil Penelitian, 2019 (Data Diolah)

Nilai tolerance dan VIF dapat dilihat pada tabel 5 diatas menunjukkan bahwa untuk variabel skeptisme, pengalaman auditor, dan self efficacy berada diatas 0,10 dan dibawah 10. Dengan demikian pada uji multikolinearitas tidak terjadi korelasi antar variabel independent.

\section{Uji Heteroskedastisitas}

Ada beberapa cara untuk menguji ada tidaknya situasi heteroskedastisitas dalam varian error terms untuk model regresi. Dalam penelitian ini akan digunakan metode chart (grafik scatterplot), dengan dasar pemikiran bahwa: 1) Jika ada pola tertentu, seperti titik-titik yang membentuk pola tertentu yang teratur (bergelombang, melebar kemudian menyempit), maka mengindikasikan telah terjadi heteroskedastisitas; dan 2) Jika tidak ada pola yang jelas, serta titik menyebar keatas dan dibawah angka 0 pada sumbu Y, maka tidak terjadi heteroskedastisitas

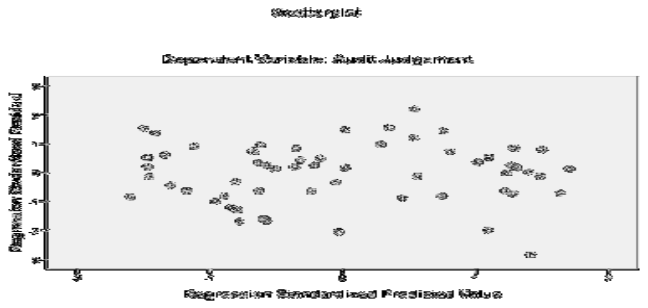

Gambar 3 Hasil Uji Heteroskedastisitas dengan Scatterplot

Sumber : Hasil Penelitian, 2019 (Data Diolah)

Grafik scatterplot pada gambar 3, terlihat bahwa titik-titik menyebar dengan pola yang tidak jelas baik diatas maupun dibawah angka nol (0) pada sumbu Y, tidak 
berkumpul di satu tempat, sehingga dari grafik scatterplot dapat disimpulkan bahwa tidak terjadi heteroskedastisitas pada model regresi.

Pendeteksian ada tidaknya heteroskedastisitas bisa juga dilakukan dengan menggunakan metode glejser test. Uji glejser ini dilakukan dengan meregresikan variabel-variabel bebas terhadap nilai absolute residual. Sebagai pengertian dasar, residual adalah selisih antara nilai observasi dengan nilai prediksi, dan absolut adalah nilai mutlaknya. Jika nilai signifikansi antara variabel independent dengan residual lebih dari 0,05 maka tidak terjadi heteroskedastisitas.

Tabel 6. Hasil Uji Glejser

\begin{tabular}{|c|c|c|c|c|c|c|}
\hline & & \multicolumn{3}{|c|}{ Coefficients } & \multirow{3}{*}{$\mathrm{t}$} & \multirow{3}{*}{ Sig. } \\
\hline \multirow[t]{2}{*}{ Model } & & \multicolumn{2}{|c|}{$\begin{array}{c}\text { Unstandardized } \\
\text { Coefficients }\end{array}$} & $\begin{array}{c}\text { Standardized } \\
\text { Coefficients }\end{array}$ & & \\
\hline & & $\mathrm{B}$ & Std. Error & Beta & & \\
\hline \multirow[t]{4}{*}{1} & (Constant) & 2,777 & 1,620 & & 1,715 & ,092 \\
\hline & Skeptisme &,- 015 & ,078 &,- 040 &,- 188 &, 852 \\
\hline & $\begin{array}{l}\text { Pengalaman } \\
\text { Auditor }\end{array}$ & ,105 & ,108 & 230 & ,976 & ,333 \\
\hline & Self Efficacy &,- 050 & ,054 &,- 213 &,- 928 & ,357 \\
\hline
\end{tabular}

a. Dependent Variable: $A B S \_R E S$

Sumber: Hasil Penelitian, 2019 (Data Diolah)

Hasil uji glejser pada tabel 6 diatas menunjukkan nilai signifikansi dari skeptisme $0,852>0,05$, pengalaman auditor $0,333>0,05$, dan self efficacy $0,357>0,05$, dengan demikian dari hasil uji glejser dapat dikatakan tidak terjadi masalah heteroskedastisitas karena nilai signifikansi dari ketiga variabel independent lebih besar dari 0,05 .

\section{Hasil Analisis Data Penelitian}

Model Penelitian

Pengujian hipotesis yang digunakan dalam penelitian adalah dengan menggunakan analisis regresi linear berganda. Model regresi yang digunakan adalah sebagai berikut:

Tabel 7. Hasil Persamaan Regresi

\begin{tabular}{|c|c|c|c|c|c|c|}
\hline \multirow[t]{2}{*}{ Model } & & \multicolumn{2}{|c|}{$\begin{array}{c}\text { Unstandardized } \\
\text { Coefficients }\end{array}$} & \multirow{2}{*}{$\begin{array}{c}\begin{array}{c}\text { Standardized } \\
\text { Coefficients }\end{array} \\
\text { Beta }\end{array}$} & \multirow[t]{2}{*}{$\mathrm{t}$} & \multirow[t]{2}{*}{ Sig } \\
\hline & & $\mathrm{B}$ & Std. Error & & & \\
\hline \multirow[t]{4}{*}{1} & (Constant) & $-1,680$ & 2,740 & &,- 613 & ,542 \\
\hline & Skeptisme & ,393 & ,132 &, 324 & 2,968 & ,004 \\
\hline & $\begin{array}{l}\text { Pengalaman } \\
\text { Auditor }\end{array}$ & ,482 & , 183 & ,316 & 2,634 & 011 \\
\hline & Self Efficacy &, 238 & 091 & ,304 & 2,601 & ,012 \\
\hline
\end{tabular}

a. Dependent Variable: Audit Judgement

Sumber: Hasil Penelitian, 2019 (Data Diolah) 


\section{Audit Judgement $=-1,680+0,393$ Skeptisme + 0,482 Pengalaman Auditor + 0,238 Self \\ Efficacy $+\mathrm{e}$}

Makna dari persamaan regresi linear berganda diatas adalah: 1) Konstanta sebesar -1,680 menyatakan bahwa jika skeptisme, pengalaman auditor, dan self efficacy bernilai 0 atau konstan maka audit judgement sebesar -1,680 satuan; 2) Koefisien regresi skeptisme sebesar 0,393 dan bernilai positif, hal ini menyatakan bahwa setiap kenaikan skeptisme 1 satuan akan meningkatkan audit judgement sebesar 0,393 satuan dengan anggapan variabel lainnya tetap; 3) Koefisien regresi pengalaman auditor sebesar 0,482 dan bernilai positif, hal ini menyatakan bahwa setiap kenaikan pengalaman auditor 1 satuan akan meningkatkan audit judgement sebesar
0,482 satuan dengan anggapan variabel lainnya tetap; dan 4) Koefisien regresi self efficacy sebesar 0,238 dan bernilai positif, hal ini menyatakan bahwa setiap kenaikan self efficacy 1 satuan akan meningkatkan audit judgement sebesar 0,238 satuan dengan anggapan variabel lainnya tetap.

\section{Koefisien Determinasi Hipotesis}

Koefisien determinasi ditujukan untuk mengetahui seberapa besar kemampuan model dalam menerangkan variabel terikat. Jika koefisien determinasi $\left(\mathrm{R}^{2}\right)$ semakin besar atau mendekati 1, maka dapat dikatakan bahwa kemampuan variabel bebas $(\mathrm{X})$ adalah bebas terhadap variabel terikat (Y).

Tabel 8 Hasil Koefisien Determinasi Model Summary

\begin{tabular}{lcccc}
\hline Model & R & R Square & $\begin{array}{l}\text { Adjusted } \\
\text { R Square }\end{array}$ & $\begin{array}{c}\text { Std. Error } \\
\text { of the } \\
\text { Estimate }\end{array}$ \\
\hline 1 &, 864 &, 747 &, 734 & 3,247 \\
\hline a. & Predictors: & (Constant), Self Efficacy, Skeptisme, Pengalaman Auditor \\
b. Dependent Variable: Audit Judgement \\
Sumber: Hasil Penelitian, 2019 (Data Diolah)
\end{tabular}

Berdasarkan tabel 8, diperoleh bahwa nilai koefisien determinasi hipotesis adalah 0,734. Hal ini menunjukkan bahwa $73,4 \%$ variasi variabel audit judgement $(\mathrm{Y})$ dapat dijelaskan oleh variabel skeptisme $\left(\mathrm{X}_{1}\right)$, pengalaman auditor $\left(\mathrm{X}_{2}\right)$, dan self efficacy $\left(\mathrm{X}_{3}\right)$. Sisanya $26,6 \%$ merupakan variabel lain yang tidak diteliti dalam penelitian ini seperti preferensi klien, kredibilitas klien, kompleksitas tugas, locus of control, persepsi etis, dan lain sebagainya.

\section{Pengujian Hipotesis Secara Simultan}

Pengujian hipotesis secara simultan (uji f) dilakukan untuk menguji bagaimana pengaruh antara variabel-variabel independent secara bersama-sama terhadap variabel dependent. Berikut adalah hasil pengujian hipotesis secara simultan : 
Tabel 9. Hasil Uji F

\begin{tabular}{|c|c|c|c|c|c|c|}
\hline \multicolumn{7}{|c|}{ ANO VA } \\
\hline Model & & Sum of Squares & Df & Mean Square & $\mathrm{F}$ & Sig. \\
\hline 1 & $\begin{array}{l}\text { Regression } \\
\text { Residual } \\
\text { Total }\end{array}$ & $\begin{array}{l}1745,687 \\
590,246 \\
2335,933\end{array}$ & $\begin{array}{l}3 \\
56 \\
59\end{array}$ & $\begin{array}{l}581,896 \\
10,540\end{array}$ & 55,208 & $000^{\mathrm{a}}$ \\
\hline
\end{tabular}

a. Predictors: (Constant), Self Efficacy, Skeptisme, Pengalaman Auditor

b. Dependent Variable: Audit Judgement Sumber: Hasil Penelitian, 2019 (Data Diolah)

Berdasarkan hasil uji $\mathrm{F}$ pada tabel 9, nilai $F_{\text {hitung }}$ sebesar 55,208. Pada derajat bebas $1\left(\mathrm{df}_{1}\right)=\mathrm{k}-1=4-1=3$, dan derajat bebas $\left(\mathrm{df}_{2}\right)=\mathrm{n}-\mathrm{k}=60-4=56$, dimana $\mathrm{n}=$ jumlah sampel, $\mathrm{k}=$ jumlah variabel, maka nilai $\mathrm{F}_{\text {tabel }}$ pada taraf kepercayaan signifikansi 0,05 adalah 2,77, dengan demikian dari hasil perhitungan SPSS diperoleh nilai $\mathrm{F}_{\text {hitung }}>$ $\mathrm{F}_{\text {tabel }}=55,208>2,77$ dengan tingkat signifikansi 0,000. Dikarenakan $\mathrm{F}_{\text {hitung }}>\mathrm{F}_{\text {tabel }}$ $=55,208>2,77$ dengan tingkat signifikansi $0,000<0,05$, maka Ha diterima artinya skeptisme, pengalaman auditor, dan self efficacy secara simultan berpengaruh signifikan terhadap audit judgement pada Kantor Akuntan Publik di Medan.

\section{Pengujian Hipotesis Secara Parsial}

Pengujian hipotesis secara parsial (uji t) dilakukan untuk menguji bagaimana pengaruh variabel-variabel independent secara individual terhadap variabel dependent. Berikut adalah hasil pengujian hipotesis secara parsial :

Tabel 10. Hasil Uji t

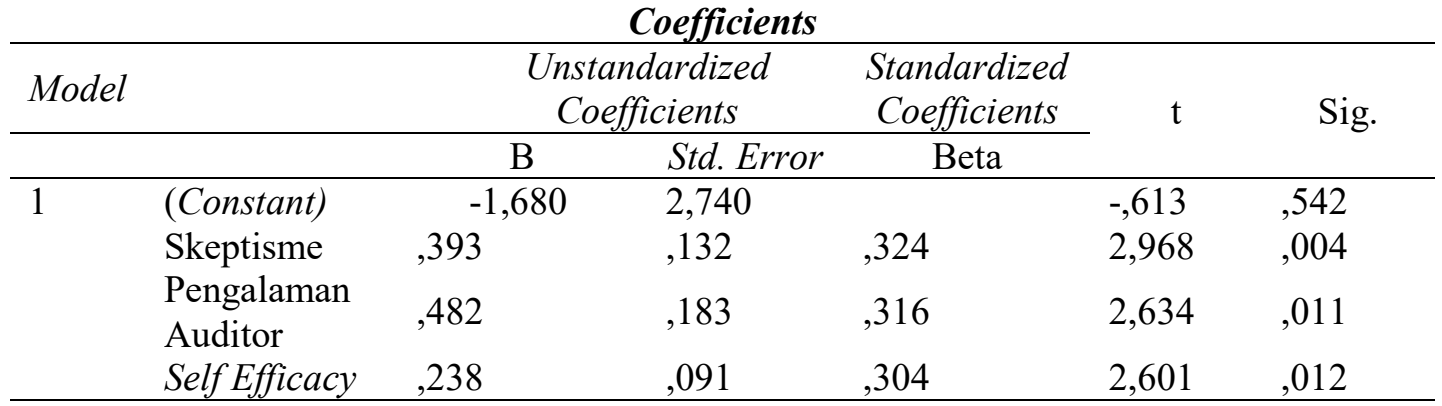

a. Dependent Variable: Audit Judgement Sumber: Hasil Penelitian, 2019 (Data Diolah)

Berdasarkan hasil uji t pada tabel 10 , nilai tabel untuk df $=\mathrm{n}-\mathrm{k}=60-4=56$ dan signifikansi 0,05 pada uji signifikansi 2 arah adalah sebesar 2,00324. Dengan demikian hasil dari uji $\mathrm{t}$ dapat dijelaskan sebagai berikut:

Hasil perhitungan uji $\mathrm{t}$ secara parsial diperoleh nilai $t_{\text {hitung }}$ skeptisme sebesar 2,968 dengan nilai signifikansi sebesar 0,004 . Nilai 
$t_{\text {hitung }}>t_{\text {tabel }}$ atau 2,968 $>2,00324$ dengan tingkat signifikansi $0,004<0,05$ maka $\mathrm{H}_{\mathrm{a}}$ diterima artinya skeptisme secara parsial berpengaruh positif dan signifikan terhadap audit judgement pada Kantor Akuntan Publik di Medan.

Hasil perhitungan uji t secara parsial diperoleh nilai $t_{\text {hitung }}$ pengalaman auditor sebesar 2,634 dengan nilai signifikansi sebesar 0,011 . Nilai $t_{\text {hitung }}>t_{\text {tabel }}$ atau 2,634 $>$ 2,00324 dengan tingkat signifikansi 0,011 < 0,05 maka $\mathrm{H}_{\mathrm{a}}$ diterima artinya pengalaman auditor secara parsial berpengaruh positif dan signifikan terhadap audit judgement pada Kantor Akuntan Publik di Medan.

Hasil perhitungan uji $\mathrm{t}$ secara parsial diperoleh nilai $\mathrm{t}_{\text {hitung }}$ self efficacy sebesar 2,601 dengan nilai signifikansi sebesar 0,012. Nilai $t_{\text {hitung }}>t_{\text {tabel }}$ atau 2,601 $>2,00324$ dengan tingkat signifikansi $0,012<0,05$ maka $\mathrm{H}_{\mathrm{a}}$ diterima artinya self efficacy secara parsial berpengaruh positif dan signifikan terhadap audit judgement pada Kantor Akuntan Publik di Medan.

\section{Pembahasan Hasil Penelitian}

\section{Pengaruh Skeptisme Terhadap Audit Judgement}

Hasil analisis menunjukkan bahwa skeptisme berpengaruh positif dan signifikan terhadap audit judgement pada Kantor Akuntan Publik di Medan dengan nilai $t_{\text {hitung }}>t_{\text {tabel }}$ atau 2,968 $>2,00324$ dan nilai signifikan $0,004<0,05$.

Hasil penelitian ini sejalan dengan hasil penelitian Operasianti et al. (2015) yaitu skeptisme berpengaruh positif terhadap audit judgement.

Hasil penelitian ini sejalan dengan teori yang dikemukakan oleh Sukendra et al. (2015), auditor bertanggung jawab untuk memberikan opini terhadap hasil audit yang telah dilakukan dengan baik dan benar. Untuk mencapai hal tersebut, pengauditan harus direncanakan dan dilakukan dengan sikap skeptisme profesional dalam segala hal yang terkait dengan kegiatan pengauditan.

Sikap skeptisme yang selalu disertai dengan pikiran yang selalu mempertanyakan dan melakukan evaluasi secara kritis terhadap bukti audit yang telah diberikan klien. Auditor sudah seharusnya menggunakan pengetahuan, keterampilan, dan kemampuan yang dituntut oleh profesi akuntan publik dalam melaksanakan tugas audit dengan cermat dan saksama sehingga judgement yang diberikan akan tepat. Dapat disimpulkan dengan semakin tinggi skeptisme dalam diri seorang auditor maka audit judgement akan semakin tinggi juga.

\section{Pengaruh Pengalaman Auditor Terhadap Audit Judgement}

Hasil analisis menunjukkan bahwa pengalaman auditor berpengaruh positif dan signifikan terhadap audit judgement pada Kantor Akuntan Publik di Medan dengan nilai $t_{\text {hitung }}>t_{\text {tabel }}$ atau 2,634 $>2,00324$ dan nilai signifikan $0,011<0,05$.

Hasil penelitian ini sejalan dengan hasil penelitian Magdalena et al. (2014: 7) 
yaitu pengalaman auditor berpengaruh positif terhadap audit judgement.

Hasil penelitian ini sejalan dengan teori yang dikemukakan oleh Pertiwi dan Ketut (2017), dimana semakin tinggi pengalaman kerja seorang auditor maka semakin tepat audit judgement yang akan dinyatakan oleh auditor. Dengan meningkatnya pengalaman kerja yang diperoleh akan semakin meningkatnya keahlian audit yang dimiliki oleh auditor. Auditor berpengalaman juga dapat mengindentifikasi kesalahan dengan lebih baik dan mereview analitis. Semakin banyak pengalaman seseorang maka akan semakin trampil melakukan pekerjaan dan semakin baik kemampuan berpikir saat bertindak untuk mencapai tujuan yang telah ditetapkan.

Pengalaman seorang auditor akan semakin bertambah seiring dengan berjalannya waktu, maka auditor akan memiliki pengetahuan lebih dalam melakukan penugasan audit, termasuk dalam memberikan opini audit. Ada kalanya auditor harus mempertimbangkan (judgement) dalam memberikan opini audit atas laporan keuangan klien. Oleh karena itu, semakin banyak pengalaman seorang auditor maka audit judgement seorang auditor akan semakin baik.

\section{Pengaruh Self Efficacy Terhadap Audit Judgement}

Hasil analisis menunjukkan bahwa self efficacy berpengaruh positif dan signifikan terhadap audit judgement pada Kantor
Akuntan Publik di Medan dengan nilai $t_{\text {hitung }}>t_{\text {tabel }}$ atau 2,601 $>2,00324$ dan nilai signifikan $0,012<0,05$.

Hasil penelitian ini sejalan dengan hasil penelitian Rumengan et al. (2018) yaitu self efficacy berpengaruh positif dan signifikan terhadap audit judgement.

Hasil penelitian ini sejalan dengan teori yang dikemukakan oleh Iskandar dan Zuraidah (2011 : 30), self efficacy yang tinggi akan meningkatkan kinerja audit judgement. Seorang individu dengan memiliki self efficacy yang tinggi akan senantiasa lebih cenderung untuk mempertimbangkan, mengevaluasi, dan menggabungkan kemampuan yang diketahuinya sebelum pada akhirnya dia menentukan suatu pilihan.

Self efficacy dinilai sebagai suatu keyakinan seseorang terhadap dirinya sendiri akan kemampuan yang dimiliki dalam mencapai suatu hasil tertentu maupun menyelesaikan tugas tertentu. Seorang auditor yang memiliki self efficacy tinggi akan membuat keraguan dalam dirinya menjadi lebih sedikit, auditor juga cenderung untuk tidak mudah menyerah dalam mengatasi tugas audit yang dihadapi meski tugas tersebut menjadi semakin rumit dan kompleks. Dengan demikian, semakin tinggi self efficacy auditor maka ia akan mampu membuat audit judgement yang lebih baik.

\section{Kesimpulan dan Saran}

Kesimpulan dari hasil penelitian ini adalah:

1) Skeptisme berpengaruh positif dan 
signifikan terhadap audit judgement pada Kantor Akuntan Publik di Medan; 2) Pengalaman auditor berpengaruh positif dan signifikan terhadap audit judgement pada Kantor Akuntan Publik di Medan; 3) Self efficacy berpengaruh positif dan signifikan terhadap audit judgement pada Kantor Akuntan Publik di Medan; 4) Skeptisme, pengalaman auditor, dan self efficacy berpengaruh positif dan signifikan terhadap audit judgement pada Kantor Akuntan Publik di Medan; dan 5) Dari hasil uji koefisien determinasi menunjukkan $73,4 \%$ variasi variabel audit judgement (Y) dapat dijelaskan oleh variabel skeptisme $\left(\mathrm{X}_{1}\right)$, pengalaman auditor $\left(\mathrm{X}_{2}\right)$, dan self efficacy $\left(\mathrm{X}_{3}\right)$ sedangkan $26,6 \%$ dijelaskan oleh variabel lain yang tidak digunakan pada penelitian ini.

Saran-saran yang berguna diantaranya: Bagi Kantor Akuntan Publik di Medan: 1) Sikap skeptisme telah dimiliki oleh sebagian besar auditor Kantor Akuntan Publik di Medan, namun terdapat salah satu KAP yang memiliki nilai variabel skeptisme terendah, maka diharapkan untuk lebih meningkatkan sikap skeptismenya, sehingga mampu memberikan audit judgement yang lebih baik. Adapula KAP yang memperoleh nilai variabel skeptisme tertinggi, dan diharapkan untuk mempertahankannya, supaya audit judgement yang diberikan semakin tepat dan benar; 2) Pengalaman auditor berpengaruh dalam penentuan audit judgement, dalam hal ini terdapat salah satu KAP memperoleh nilai terendah untuk variabel ini, dikarenakan KAP tersebut memiliki jumlah auditor junior yang cukup dominan, sehingga diharapkan auditor junior tersebut dapat belajar dari auditor senior dalam penanganan tugas-tugas audit supaya mampu memberikan audit judgement yang baik dan tepat. Di sisi lain, KAP dengan jumlah auditor senior yang lebih dominan, memiliki nilai tertinggi untuk variabel ini, diharapkan para auditor ini juga mampu memberikan audit judgement yang semakin tepat; 3) Self efficacy sebagai evaluasi seorang auditor mengenai kemampuannya dalam melaksanakan tugas tertentu. Dimana, terdapat salah satu KAP yang memperoleh nilai cukup rendah pada variabel self efficacy, diharapkan auditor dapat lebih mengetahui kemampuannya dalam penyelesaian tugas audit serta mampu mengelola tugas audit dengan baik supaya audit judgement yang berikan tepat dan benar. Terdapat KAP yang memperoleh nilai variabel self efficacy tertinggi juga, dalam hal ini para auditor ini diharapkan mampu mempertahankannya, sehingga tugas audit dapat terselesaikan dengan tepat dan benar disertai dengan pemberian audit judgement yang semakin tepat; dan Auditor Kantor Akuntan Publik di Medan masih perlu meningkatkan sikap skeptisme, pengalaman auditor dengan memperoleh bimbingan dari auditor senior, serta self efficacy dengan pengelolaan tugas audit yang lebih baik agar auditor mampu memberikan audit judgement yang tepat. 
Bagi peneliti selanjutnya, disarankan untuk menambah variabel lain di luar dari variabel yang diteliti oleh peneliti seperti preferensi klien, kredibilitas klien, kompleksitas tugas, locus of control, persepsi etis, dan lain sebagainya.

\section{Daftar Pustaka}

Jurnal:

Gracea, Angel., Lintje Kalangi dan Sintje Rondonuwu. 2017. Pengaruh Keahlian Auditor, Pengetahuan Auditor dan Kompleksitas Tugas Terhadap Audit Judgment (Studi kasus pada BPK RI Perwakilan Provinsi Sulawesi Utara). Jurnal EMBA. Vol.5 No.2. Hal 26272636.

Iskandar, Takiah Mohd dan Zuraidah Mohd Sanusi. 2011. Assessing The Effect of Self Efficacy and Task Complexity on Internal Control Audit Judgement. Asian Academy of Management Journal of Accounting and Finance (AAMJAF). Vol.7 No.1. Hal 29-52.

Magdalena, Maria., Oerip Liana Sofiani dan Elisa Tjondro. 2014. Pengaruh Tekanan Ketaatan, Pengalaman Audit, dan Audit Tenure Terhadap Audit Judgement. Tax \& Accounting Review, Vol. 4 No. 1.

Nadirsyah., Mirna Indriani dan Iskandar Usman. 2011. Pengaruh Anggaran Waktu Audit, Kompleksitas Dokumen Audit dan Pengalaman Auditor Terhadap Pertimbangan Audit Sampling Pada Badan Pemeriksa Keuangan (BPK) Republik Indonesia Perwakilan Provinsi Aceh. Jurnal Telaah \& Riset Akuntansi. Vol. 4, No.2. Hal 176-186.

Operasianti, Siti Amelia., Hendra Gunawan dan Mey Maemunah. 2015. Pengaruh Insentif Kerja, Persepsi Etis, dan Skeptisme Profesional terhadap Audit
Judgement (Survey pada Kantor Akuntan Publik di Kota Bandung). Prosiding Penelitian Sivitas Akademika Unisba (Sosial dan Humaniora). (Hal 43-50). Agustus 2015. Bandung. Unisba.

Pertiwi, Kadek Upawita Candra dan Ketut Budiartha. 2017. Pengaruh Tekanan Ketaatan, Independensi, Pengalaman Kerja, Locus of Control Terhadap Audit Judgement Di KAP Bali. EJurnal Akuntansi Universitas Udayana. Vol.19.1. Hal 712-740.

Praditaningrum, Anugrah Suci. 2012. Analisis Faktor-Faktor yang Berpengaruh terhadap Audit Judgement (Studi pada BPK RI Perwakilan Provinsi Jawa Tengah). (Skripsi). Fakultas Ekonomika dan Bisnis. Semarang: Universitas Diponegoro.

Prihandono, Aldiansyah Utama. 2012. Hubungan Skeptisisme Profesional Auditor, Situasi Audit, Independensi, Etika, Keahlian, dan Pengalaman Dengan Keputusan Pemberian Opini Audit Oleh Auditor. (Skripsi). Fakultas Ekonomika dan Bisnis. Semarang: Universitas Diponegoro.

Rumengan, Vriska., Jantje J. Tinangon dan Sonny Pangerapan. 2018. Pengaruh Obedience Pressure dan Self Efficacy Terhadap Audit Judgement Pada Auditor Perwakilan BPKP Provinsi Sulawesi Utara. Jurnal Riset Akuntansi Going Concern. Vol.13 No.2. Hal 282289.

S Iriantika, I Made Toni dan I Ketut Budiartha. 2017. Skeptisme Profesional Sebagai Pemoderasi Pengaruh Kompleksitas Tugas dan Tekanan Ketaatan Terhadap Audit Judgement. E-Jurnal Akuntansi Universitas Udayana. Vol.18.2. Hal 1053-1081. 
Sari, Dessy Indah dan Endang Ruhiyat. 2017. Locus of Control, Tekanan Ketaatan, dan Kompleksitas Tugas terhadap Audit Judgement. Jurnal Aset (Akuntansi Riset). Vol. 9 No. 2. Hal 23-34.

Sukendra, I Putu., Gede Adi Yuniarta dan Anantawikrama Tungga Atmadja. 2015. Pengaruh Skeptisme Profesional, Pengalaman Auditor, dan Keahlian Audit Terhadap Ketetapan Pemberian Opini Oleh Auditor (Studi Empiris Pada Inspektorat Kabupaten Buleleng, Kabupaten Bangli, dan Kabupaten Karangasem). E-Journal S1 Ak Universitas Pendidikan Ganesha. Volume 3 No. 1.

Suwandi. 2015. Pengaruh Self Efficacy, Kecerdasan Emosional, Tekanan Ketaatan dan Kompleksitas Tugas Terhadap Audit Judgement Auditor (Studi Empiris pada KAP di Pekan Baru, Padang dan Batam). Jom Fekon. Vol 2, No 1. Hal 1-15.

Winarto, Yudho. 2017. Mitra Ernst \& Young Indonesia didenda US\$1 juta. http://nasional.kontan.co.id/news/mitra -ernst-young-indonesia-didenda-us-1juta. [20 Mei 2018]. 